\title{
HERMENÊUTICA FLEXÍVEL E DISCRICIONARIEDADE JUDICIAL
}

\section{HERMENEUTICS FLEXIBLE AND JUDICIAL DISCRETION}

\begin{abstract}
Eduardo Augusto Salomão Cambi
Pós-doutor em Direito pela Università degli Studi di Pavia. Doutor e mestre em Direito pela Universidade Federal do Paraná (UFPR). Professor da Universidade Estadual do Norte do Paraná (UENP) e da Universidade Paranaense (UNIPAR). Promotor de Justiça no Estado do Paraná. Assessor da Procuradoria Geral de Justiça do Paraná. Membro colaborador da Comissão de Direitos Fundamentais do Conselho Nacional do Ministério Público (CNMP). Coordenador Nacional do Projeto João Cidadão de Educação em Direitos Humanos do CNMP. Coordenador Estadual do Movimento Paraná Sem Corrupção. Coordenador Estadual da Comissão de Prevenção e Controle Social da Rede de Controle da Gestão Pública do Paraná. Diretor Financeiro da Fundação Escola do Ministério Público do Estado do Paraná (FEMPAR). Diretor de Pesquisa do Instituto Paranaense de Direito Processual. Foi assessor de Pesquisa e Política Institucional da Secretaria de Reforma do Judiciário do Ministério da Justiça (2012-2014). eduardocambi@hotmail.com

LUNA STIPP Mestranda em Ciências Jurídicas pela Universidade Estadual do Norte do Paraná - UENP.Advogada. Especialista em Direito e Processo do Trabalho pela UNIDERP. Pesquisadora dos Grupos de Pesquisa "Democracia e Direitos Fundamentais" e "A Eficácia dos Direitos Fundamentais no Brasil". lunastipp@hotmail.com
\end{abstract}

\section{RESUMO}

O artigo tem como propósito discutir a discricionariedade judicial na aplicação dos princípios jurídicos, no contexto da modernidade líquida. 0 artigo procura, por meio do método de revisão bibliográfica, demonstrar as consequências e perigos na utilização de métodos interpretativos desvinculados do sistema normativo preestabelecido.

PALAVRAS-CHAVE: Decisão judicial; Discricionariedade; Fundamentação; Hermenêutica jurídica; Segurança jurídica;

\begin{abstract}
This article aims to discuss judicial discretion in the application of legal principles in the context of liquid modernity. This article, through the literature review method, demonstrate the consequences and dangers in the use of interpretative methods disconnected from the pre-established regulatory system
\end{abstract}

KEYWORDS: Judicial decision; Discretion; ; Reasons; Legal Hermeneutics; Legal certainty;

\section{SUMÁRIO}

INTRODUÇÃO; 1. LEI COMO SEGURANÇA JURÍDICA; 2. CONFLITO ENTRE NORMAS; 3. O ABANDONO DO FORMALISMO. CONCLUSÕES. REFERÊNCIAS BIBLIOGRÁFICAS

\section{INTRODUÇÃO}

É inerente à razão humana a busca da certeza em relação ao futuro. Isso reflete no meio jurídico pela previsão de regras e princípios, voltados à promoção da estabilidade, previsibilidade e segurança jurídica. 
Entretanto, a abertura do sistema jurídico, com a adoção de normas abertas e de conteúdos vagos, conduzem muitas vezes a produção de decisões judiciais imprecisas e que causam insegurança jurídica.

É certo que os juízes possuem suas próprias convicções morais, políticas, sociais e filosóficas, mas a subjetividade do julgador precisa se adequar à necessidade de objetividade e racionalidade do sistema jurídico.

Nesse contexto, é necessário discutir as possíveis formas de atuação judicial diante das questões trazidas pela hermenêutica jurídica contemporânea, para assegurar maior previsibilidade jurídica e confiança no Direito por parte dos destinatários das normas.

O texto procura analisar a discricionariedade judicial à luz da ideia de "modernidade liquida”, desenvolvida por Zygmunt Bauman.

Pretende-se, ainda, analisar os métodos interpretativos utilizados para aplicação judicial do direito.

\section{LEI COMO SEGURANÇA JURÍDICA}

No modelo de Estado Liberal, a limitação do poder estatal encontrou espaço para o desenvolvimento do Poder Legislativo, como aquele que representa diretamente o povo. As leis provenientes do Legislativo deveriam retratar os anseios da sociedade.

Tais regras serviriam para nortear as decisões judiciais, pois, ao representarem os posicionamentos sociais, seriam a fórmula para a harmonia e a segurança jurídica do povo.

As leis significaram uma conquista para a civilização, isso porque traziam a sensação de previsibilidade. Afinal, a simples circunstância de os padrões de avaliação de conduta serem conhecidos, independente do juízo de valor que a respeito destes padrões de avaliação se possa fazer, satisfaz e tranquiliza ${ }^{1}$.

Entretanto, o direito, jurídica e estruturalmente, considerado prima facie não pode ser reputado como definitivo, posto que seu conteúdo somente se revelará após a ponderação ou o

\footnotetext{
1 WAMBIER, Teresa Arruda Alvim. Precedentes e Evolução do Direito.In: Direito Jurisprudencial. Coord. Teresa Arruda Alvim Wambier. São Paulo: RT, 2012. p. 14.
} 


\section{政

balanceamento exigidos pela proteção de outros bens com ele coincidentes diante de um caso concreto ${ }^{2}$.

As normas são estabelecidas considerando o contexto e necessidade social que imperava à época da sua criação. Ainda, na medida que as pretensões aumentam, as satisfações delas tornam-se cada vez mais complexas ${ }^{3}$.

Por isso, a atenção à efetividade do conteúdo normativo deve ser conjugada com a possibilidade de sua execução. Por exemplo, a Constituição Federal de 1988 buscou proporcionar igualdade e assegurar princípios que foram suprimidos pelo regime ditatorial anterior.

Stéphane Monclaire ${ }^{4}$, pesquisador francês que dedicou parte de suas investigações ao processo constituinte brasileiro de 1987, ressalta o pluralismo político e social daquele momento, pois o número e a diversidade de grupos mobilizados impressionam. Todo mundo foi afetado pela onda de discussões sobre os princípios que a nova Constituição estabeleceu ${ }^{5}$, a ponto de se afirmar que nenhuma das Constituições anteriores conseguiu expressar o sentimento das pessoas, como a de 1988. Nenhuma delas foi tão influenciada diretamente pela sociedade ${ }^{6}$. $\mathrm{Na}$ ocasião da constituinte de 1988, numerosas delegações representaram diferentes seguimentos da população brasileira, o que assegurou o caráter compromissório e plural da Constituição ${ }^{7}$.

A Constituição Federal de 1988 possibilitou transformações políticas, culturais e ideológicas estabelecendo paradigmas que ainda estão em processo de consumação.

Isso somente foi possível pela participação de diversos atores políticos e sociais. Tal Constituição pluralista aumentou o papel do Estado na promoção e realização de direitos sociais. Aliás, em uma Constituição pluralista não existe um único soberano efetivo: cada sujeito social busca melhorar sua própria posição, mas, em um contexto de lutas que envolve muitas forças

2 CAMBI. Eduardo. Neopositivismo e Neoconstitucionalismo. Direitos fundamentais, políticas públicas e protagonismo judiciário. São Paulo: Almedina, 2016. p.121.

3 BOBBIO, Noberto. A era dos Direitos. São Paulo: Elsevier, 2004 . p.60.

4 MONCLAIRE, Stéphane. As grandes características do último processo constituinte brasileiro. Revistade informação legislativa, v. 45, n. 179, p. 277-295, jul./set. 2008, p. 287.

5 GUTEMBERG, Luiz. Mapa geral das ideias e propostas para a nova Constituição. Brasília: Ministério da Justiça/ Fundação Petrônio Portella, 1987. p.13.

6 FALCÃO, João Emílio. Entrevista ao Jornal da Constituinte, $n^{\circ} 63$, caderno 1. 5 out. 1988.

7 RIBEIRO, Ronaldo Paixão. Maintenant, à lafindutunnel, brillelalumière. Entrevista ao Jornal da Constituinte. $\mathrm{n}^{\circ} 63$, caderno 1. 5 out. 1988. p.3. 


\section{政

políticas, econômicas e culturais, o que elimina a possibilidade de prevalecer pensamentos únicos, mas também não elimina o caráter conflituoso, próprio da Democracia ${ }^{8}$.

Desse modo, as Constituições pluralistas, como a brasileira de 1988, passam a ser instrumentos comuns ao alcance e poder de todos na sua luta para transformar a realidade.

Trata-se de uma luta pacífica, porque a legitimidade do ato deve estar calcada nas regras procedimentais preestabelecidas no próprio ordenamento jurídico.

A interpretação e a aplicação da Constituição assume crucial importância para assegurar sua supremacia, força normativa e irradiação pela ordem jurídica, bem como para alterar a cultura social'.

Ronald Dworkin defende a aplicação dos princípios e das fontes do direito dentre outras hipóteses quando a lei for obscura ou omissa. Procura traçar uma teoria normativa de lei apta não apenas a identificar a lei, mas também a justificá-la moralmente do melhor modo possível ${ }^{10}$.

Assim, ao se posicionar contra os positivistas, o filósofo norte-americano, pretende demonstrar que os aplicadores do direito recorrem a padrões que não funcionam como regras, mas operam diferentemente, como princípios, políticas e outros tipos de padrões ${ }^{11}$.

Ao se pensar principiologicamente dentro do sistema jurídico é possível alinhar segurança à justiça social, passível de percepção intersubjetiva, na dialética normativo- axiológica do sistema, que o horizonte da principiologia abre para o operador do direito ${ }^{12}$.

Portanto, a legitimidade da aplicação judicial descansa na previsibilidade legal e procedimental de modo que qualquer ato que o extrapole deve ser retido no controle de constitucionalidade.

Para Jürgen Habermas, o direito moderno tira dos indivíduos o fardo das normas morais e as transfere para as leis que garantem a compatibilidade das liberdades de ação. Estas obtêm sua legitimidade por meio de um processo legislativo que, por sua vez, se apoia no princípio da soberania do povo. Com o auxílio dos direitos que garantem aos cidadãos o exercício de sua

8 ZAGREBELSKY, Gustavo. La ley e sujusticia. Tres capítulos de justiciaconstitucional. Madri: Editorial Trotta, 2014. p. 302.

LIMA, Tadeu. Augimeri de Goes Neoconstitucionalismo: um breve panorama.Argumenta Journal Law, Jacarezinho PR. 2015, p.169.

${ }_{10}$ IKAWA, Daniela R. HART, Dworkin e discricionariedade. Lua nova no 61- 2004. p. 97-113.

11 DWORIN, Ronald. Levando o direito a sério.São Paulo: Martins Fontes. 2011.p. 36

12 ARRONE, Ricardo. Por uma nova hermenêutica dos Direitos Reais Limitados. Rio de Janeiro: Renovar. 2001.p.76 


\section{政

autonomia política, é possível explicar o paradoxo do surgimento da legitimidade a partir da legalidade ${ }^{13}$.

Essa característica não se observava nas monarquias absolutistas em que a própria existência do poder real, soberano e transcendente bastava para justificar qualquer postura do monarca. Assim, nas sociedades ocidentais, desde a Idade Média, até a Revolução Francesa, a elaboração do pensamento jurídico se fez essencialmente em torno do poder real. A reativação do Direito Romano do século XII foi efetivamente um dos instrumentos técnicos e construtivos mais importantes do poder monárquico autoritário, administrativo e absolutista ${ }^{14}$.

O Direito, na Idade Média, refletia uma sociedade estática, hierarquicamente organizada em classes e estamentos, tendo como função principal tutelar a propriedade privada.

A superação da soberania do monarca pela do povo ocorreu com a Revolução Francesa quando movimentos sociais, promovidos pela burguesia e depois pela classe laboral, ganham espaço no Poder Legislativo.

De um Direito fragmentado, voltado a sistematizar a vontade dos monarcas e dos Senhores Feudais, o Iluminismo eliminou privilégios, inaugurando o Estado Liberal, baseado em leis comuns que atendessem os interesses da burguesia que o financiava.

No século XVIII, esse novo Estado Liberal inaugurou um período de codificações para uniformizar o sistema normativo.

De mero expectador, as pessoas passam a ser titulares de direitos, cidadãos responsáveis pelas mudanças sociais.

A segurança jurídica é uma preocupação existente desde a Declaração de Direitos do Homem e do Cidadão de 1789, cujo artigo $6^{\circ}$ dispunha: “A lei é a expressão da vontade geral. Todos os cidadãos têm o direito de concorrer, pessoalmente ou através de mandatários, para a sua formação. Ela deve ser a mesma para todos, seja para proteger, seja para punir. Todos os cidadãos são iguais a seus olhos $e$ igualmente admissíveis a todas as dignidades, lugares $e$ empregos públicos, segundo a sua capacidade e sem outra distinção que não seja a das suas virtudes e dos seus talentos".

A codificação do Direito Civil representou o ápice da uniformização do direito a partir do Código Napoleônico de 1804, houve um período de intensas codificações que se espalhou por

\footnotetext{
13 HABERMAS, Jürgen.Direito e democracia: entre facticidade e validade. Vol. 1. 2. ed. Tradução de Flávio Beno Siebeneichler. Rio de Janeiro: Tempo Brasileiro, 2003. p. 184.

14 SILVA, Ovídio Araújo Baptista da. Processo e Ideologia: o paradigma racionalista. ${ }^{\mathrm{a}}$ ed. Rio de Janeiro: Forense, 2006.p.44.
} 


\section{政

toda a Europa. Este fenômeno representou a garantia de separação entre a sociedade civil e o Estado. A segurança jurídica estava baseada no novo papel do intérprete, que se baseava na simples aplicação da lei.

Após a $2^{a}$ Guerra Mundial, com a reconstrução dos Estados, houve maior aproximação do Direito Público com o Direito Privado. O contrato perdeu força para a lei e o Código Civil deixou de ser o centro do ordenamento jurídico, cedendo espaço para as Constituições ${ }^{15}$.

Observa-se, portanto, que a autonomia privada passa a sofrer restrições com o surgimento de estatutos e convenções que resguardam interesses mais amplos que não podem ser mitigados pelos contratantes. Além disso, com a incorporação das cláusulas gerais, dentre elas a da função social do contrato, surge a possibilidade de maiores questionamentos de conceitos e princípios que constituem novos desafios para conferir ao Direito segurança jurídica.

Nos tempos modernos, a segurança jurídica deve ser associada à metáfora da fluidez dos líquidos. Zygmunt Bauman compara o passado aos sólidos que, pela sua resistência e estabilidade, além das suas dimensões espaciais, poderiam ser conservados por muito tempo.

Assim, as leis antigas e os citados contratos tinham as características dos sólidos, devendo-se perpetuar no tempo. Entretanto, em um processo chamado derretimento dos sólidos $^{16}$, fez com que, na modernidade contemporânea, o que antes era sólido e seguro acabasse por se tornar fluído.

Esse é o curso comum da modernidade. Isso porque estamos em movimento mesmo que fisicamente estejamos imóveis; vale dizer, a imobilidade não é uma opção realista em um mundo em permanente mudança ${ }^{17}$.

As leis modernas, por serem fragmentadas, ocasionais e vagas não mais expressam a vontade geral e demandam uma hermenêutica flexível capaz de possibilitar a solução mais adequada para os casos concretos e assim acompanhar os movimentos e anseios sociais.

15 VIAL, Sophia martini. O fenômeno da codificação e da recodificação no Direito Privado. Irevista de direito privado, vol. 64, out./dez. 2015, p. 19.

16 BAUMAN, Zygmunt. Modernidad Líquida.Buenos Aires: Fondo de Cultura Económica, 2002 p.9.

17 BAUMAN, Zygmunt.Globalização: As conseqüências humanas. Rio de Janeiro:Zahar,1999. p.8 


\section{政

\section{CONFLITO ENTRE NORMAS}

Conhecido os fatos e as motivações, o método exige do intérprete que conheça o instrumental jurídico colocado a sua disposição ${ }^{18}$.

$\mathrm{Na}$ tentativa de traçar o melhor método para a obtenção do fim desejado é que até o século XIX, predominou o processo de subsunção do fato ao tipo legal para a resolução dos casos concretos.

Dessa forma, o direito positivamente válido retirava dos julgadores o peso das grandes exigências cognitivas, motivacionais e organizacionais que uma moral ajustada segundo a consciência subjetiva acaba impondo a eles ${ }^{19}$.

Sendo a lei a expressão da vontade geral, não havia dificuldade de o juiz aplicar a regra jurídica, pois assim não se violariam as expectativas sociais. Deste modo, a dificuldade do julgador se cingia a resolver as antinomias jurídicas, pois duas normas não poderiam ser aplicadas ao mesmo tempo, sendo necessário eliminar uma delas, senão as duas ${ }^{20}$.

As antinomias poderiam ser solúveis (ou aparentes) e insolúveis (ou reais). Nem todas as antinomias são solúveis, porque há casos em que não se pode aplicar nenhuma das regras pensadas para a solução de antinomias. Além disso, há situações em que se podem aplicar ao mesmo tempo duas ou mais regras em conflito entre si. Por outro lado, as antinomias reais são aquelas em que o intérprete é abandonado a si mesmo ou pela falta de um critério ou por conflito entre critérios dados ${ }^{21}$.

Para a resolução das antinomias, aplicavam-se três critérios. Quando havia incompatibilidade entre normas, deveria prevalecer o critério cronológico, pelo qual lex posterior derrogat priori. A vontade posterior do legislador revoga a precedente, sendo dois atos de vontade emanados da mesma autoridade, prevalece o último ${ }^{22}$.

Há, ainda, o critério hierárquico, pelo qual entre duas normas incompatíveis, aplica-se a hierarquicamente superior: lex superior derogat inferior ${ }^{23}$. Além disso, existe o critério da especialidade pelo qual lex specialis derogat lex generalis.

\footnotetext{
18 SCHNAID, David. Filosofia do direito e interpretação. São Paulo: RT, 2004. p.215

19 HABERMAS, Jurgen. A inclusão do outro: Estudos de teoria política.São Paulo: Edição Loiola, 2002.p.289.

20 BOBBIO Noberto. Teoria do Ordenamento Jurídico.Tradução: Ari Marcelo Solon. São Paulo: EDIPRO,2011. p.95-96.

21 Idem, p.96.

22 Idem, p.97.

23 Idem. Ibidem.
} 
Nesse raciocínio clássico, impera o pensamento racionalista. A razão é o meio para a obtenção do conhecimento mais seguro do que a experiência e a observação, sendo as ciências exatas o melhor método para se obter a verdade ${ }^{24}$.

Desse modo, a possibilidade de interpretação pelo aplicador do direito ou a inserção de qualquer juízo de valor é praticamente impensável, já que é depositado na norma o resultado correto e perfeito da solução proposta comparada a resolução de um problema matemático.

Nesse modelo racionalista, o juiz deveria apenas declarar a vontade concreta da lei ("boca da lei”), não havendo margem para a inserção de juízos de valor, os quais já estavam todos depositados na norma a ser aplicada pelo silogismo judicial.

A produção do Direito deveria ser obra exclusiva do legislador, que se supunha um ser iluminado, capaz de produzir leis tão claras e transparentes que dispensavam o trabalho do intérprete.

O fenômeno da codificação do Direito Civil, a Escola da Exegese e, depois, a teoria pura do Direito limitaram a esfera do convencimento judicial, ao buscar eliminar a perspectiva hermenêutica na compreensão do fenômeno jurídico ${ }^{25}$.

Entretanto, esse sistema não se amoldou mais a realidade, isso porque a sociedade evoluiu e junto dela surgiram novas necessidades inclusive de inovação das técnicas de aplicação das leis. A fragmentação do Direito, provocada pela inflação legislativa e a proliferação dos microssistemas, bem como o neopositivismo (que atribuiu maior força normativa aos princípios), fez com que o jurista se deparasse com situações em que o método racionalista não mais se aplica.

Porém, não se pode perder de vista que toda norma jurídica tem um propósito; toda a solução implica a projeção de seus efeitos, uma prognose dos efeitos presumíveis da decisão e da sua influência sobre os interesses ${ }^{26}$.

Considerando que os fenômenos são associados à realidade histórica e social em cujo contexto se manifestaram, pois só assim podem ser compreendidos ${ }^{27}$, é que tornou-se necessário conjulgar novos métodos de interpretação em composição com os pré-existentes.

\footnotetext{
24 ROHMANN, Chris. O Livro das ideias: pensadores, teorias e conceitos que formam nossa visão de mundo. Rio de Janeiro: Campus,2000.p.337.

25 SILVA, Ovídio Araújo Baptisda da. Op. cit. p. 16.

26 SCHNAID, David. Op. cit. p..216

27 Idem, p.211.
} 
Esse fenômeno acarretou certa inquietação na filosofia jurídica repousada na necessidade de justificação do procedimento adotado na interpretação e posterior aplicação da norma.

Surge, então, uma nova hermenêutica pensada não apenas em normas jurídicas, mas que, sobretudo fornecesse as “razões" das regras, dos princípios e dos procedimentos, que constituísse na arte da compreensão em geral ${ }^{28}$.

Nos tempos modernos, o modelo racionalista ruiu, pois, quando a lei deixou de ser percebida como simples expressão da vontade geral, quando os conceitos vagos e indeterminados passaram a integrar as normas, quando o legislador começou a adotar cláusulas gerais e quando os princípios jurídicos assumiram o mesmo ou superior status normativo das regras a solidez do Direito moldado em um mundo previsível e confortável ${ }^{29}$, deu lugar ao Direito dúctil $^{30}$ e a necessidade de uma hermenêutica flexível.

Desse modo, ampliou-se a margem de liberdade judicial na interpretação e na aplicação das normas jurídicas. Logo, pode-se afirmar que no Século XVIII predominou a força do Poder Executivo, pelas monarquias absolutistas, no Século XIX, o do Poder Legislativo, a partir do Século XX houve a expansão do Poder Judiciário ${ }^{31}$.

A expansão da jurisdição se justifica pela necessidade de aplicação dos princípios jurídicos que, além de possuir conceitos abertos, ampliam a dimensão argumentativa do direito, a exigir ponderações, já que a sua densidade normativa se revela em face das circunstâncias do caso concreto ${ }^{32}$.

Entretanto, a hermenêutica flexível dos tempos modernos não pode conduzir ao subjetivismo judicial nem ao casuísmo judiciário ${ }^{33}$ para não se premiar a discricionariedade do juiz em detrimento da segurança jurídica.

\footnotetext{
28 SCHLEIERMACHER, Friedrich D.E. Hermenêutica - Arte e técnica da interpretação. Petrópolis, RJ:Vozes; SP:Editora Universitária São Francisco,2012. p.15.

29 BAUMAN, Zygmunt. Op. cit. p. 9.

30 ZAGREBELSKY, Gustavo. Il diritto mite. Turim: Einadi, 1992.

31 CAPPELLETTI, Mauro. Juízes legisladores? Porto Alegre,1993. p.54-55.

32 MACHADO.EdinilsonDonisete. Ativismo Judicial. Letras Jurídicas pg.151.

33 CAMBI, Eduardo; MARGRAF, Alencar Frederico. Casuísmos judiciários e precedentes judiciais. Revista de processo, vol. 248, out./2015, p. 311-330.
} 


\section{(2)

\section{O ABANDONO DO FORMALISMO}

A partir do século XX, com o neopositivimo, foi abandonado o formalismo legal em favor da justiça das decisões judiciais ${ }^{34}$.

Pressupunha-se que a hermenêutica deveria se deslocar do domínio técnico e científico, estabelecendo-a no domínio filosófico, argumentando que a arte de compreender está internamente conectada com a arte de falar e de pensar ${ }^{35}$.

Somou-se a isso a chamada virada linguística (linguistic turn) que possibilitou o estudo do fenômeno jurídico pelo viés textual, conduzindo a interpretação para além da análise lógica e gramatical da linguagem.

Consequência inevitável e previsível da modernidade (“derretimento dos sólidos”), é a perda do cálculo racional dos efeitos ${ }^{36}$.

Os textos jurídicos passam a ser interpretados dentro dos contextos em que estão inseridos. Assim, o texto normativo, que anteriormente trazia certa segurança jurídica ao interesse da classe dominante, agora precisa passar pelo crivo da interpretação/aplicação dos intérpretes.

A ambiguidade da história humana passa a dar respostas diversas segundo quem as interroga e segundo o ponto de vista adotado por quem a interroga ${ }^{37}$.

Os juristas não precisam de provas para mostrar que os juízes divergem e que suas decisões com frequência refletem sua formação e seu temperamento ${ }^{38}$.

Desse modo, surge a hermenêutica flexível que retira o caráter silogístico das decisões judiciais, para se fundar em outra lógica argumentativa. Ademais, aplicação do direito não pode ser reduzida meramente a um exercício de aplicação de uma regra: o que se aplica, é o todo que o direito é, e não normas jurídicas isoladas ${ }^{39}$.

Ao intérprete resta escolher a solução que, como um todo, confira maior efetividade aos valores e princípios constitucionais com vistas a uma consciência moral ou de um consenso de justiça que opera além dos limites relacionados às suas visões subjetivas de mundo.

\footnotetext{
34 OTERO, Cleber Sanfelici. Poder Judiciário e democracia: são os juízes reféns dos sistema?Birigui: 2012. p. 59.

SCHLEIERMACHER, Friedrich D.E. Op. cit. p.15.

BAUMAN, Zygmunt . Op. cit. p.10.

37 BOBBIO, Noberto. A era dos Direitos. Cit. p.50.

38 Idem, p. 10.

39 GRAU, Eros Roberto. Porque tenho medo dos juízes (a interpretação/aplicação do direito e os princípios). São Paulo: Malheiros, 2013. p. 103.
} 
Mentalmente, todo o processo é presidido por uma lógica dialética, que usa a argumentação e o confronto de argumentos como único caminho para chegar à convicção crítica. ${ }^{40}$.

É preciso se distanciar do subjetivismo judiciário que causa insegurança judicial e, com apoio na razão prática, adotar a perspectiva de um julgamento imparcial de normas e princípios. Afinal, se cada intérprete utilizasse o sentido que ele próprio atribui ao termo, não haveria dados objetivos nem progresso em comum ${ }^{41}$.

Considerando que os princípios e normas estabelecidos normativamente exigem um reconhecimento geral, as razões postas na balança do julgador precisam ter peso epistêmico e não podem expressar tão somente o que os juízes consideram racional fazer, conforme as suas respectivas preferências pessoais.

Ao tratar da relação complementar entre direito positivo e moral autônoma, Jürgen Habermas esclarece que com a introdução de direitos subjetivos que garantem aos agentes espaços para agir de acordo com suas próprias preferências, o direito moderno como um todo faz valer o princípio de que se permite tudo que não seja explicitamente proibido ${ }^{42}$.

Todavia, há que se atentar que a permissão de uma nova visão sobre outros olhares em relação a um determinado caso pode, concomitantemente, acarretar a instabilidade e a imprevisibilidade jurídicas. Permitir que o juiz possa julgar à margem do que determina o sistema jurídico seria o mesmo que investi-lo de um poder divino, o que não se compatibiliza com o Estado Democrático de Direito, onde as decisões precisam ser rigorosamente motivadas (art. 93, inc. IX, CF) e estarem em conformidade com o ordenamento jurídico.

Ao contrário, Hebert $\mathrm{Hart}^{43}$ defende a autonomia judicial quando, diante do caso concreto, não houver uma resposta clara cabendo ao juiz decidir em conformidade com o que entende por razoável. Fosse assim, a sentença, como ato discursivo, sofreria a influência da ideologia pessoal do juiz ${ }^{44}$, com prejuízo para a razão pública ${ }^{45}$ que deve conduzir a aplicação do direito pelo Poder Judiciário.

\footnotetext{
SCHNAID, David. Filosofia do direito e interpretação. Cit. p.211.

Idem, p.10.

2 idem, p.288.

43 HART, Hebert L.A. O conceito de direito. Lisboa: Fundação Calouste Gulbenkian, 200.p51

44 MARTIN, Andreia Garcia; PIGNATARI, Nínive Daniela Guimaraes. A decisão Judicial sob a perspectiva do princípio da prevalência dos direitos humanos: A humanização da hermenêutica judicial..Birigui: Boreal, 2012. p. 47.

45 RAWLS, John. O liberalismo político. Trad. Dinah de Abreu Azevedo. Brasília: Editora Ática, 2000. p. 261.
} 
A razão pública significa um espírito de reciprocidade que fundamenta a sociedade democrática, o que se coaduna com a afirmação de valores morais-políticos para uma democracia constitucional ${ }^{46}$. Tal razão pública constitui a base para decisões judiciais, pois parte de um ponto de vista comum para a vida pública, distanciando-se de visões individuais e particulares.

A questão da justificação das decisões judiciais é relevante, pois afeta não somente a autoridade judicial, mas remete também à extensão da obrigação moral e política do indivíduo de obedecer às regras jurídicas.

Com efeito, ainda que a hermenêutica contemporânea deva ser flexível em razão da fluidez do Direito, a decisão justa deve estar fundada na correta aplicação do ordenamento jurídico. Não se esquecendo que no plano jurídico buscam-se soluções técnicas, mas que também têm repercussões políticas, econômicas e sociais. 0 juiz se depara com um problema concreto, a ser solucionado visando a realização de valores éticos ${ }^{47}$.

Logo, o intérprete, ao atribuir sentido ao texto, não pode dizer qualquer coisa, agindo arbitrariamente, como se a regra ou o princípio jurídicos tivessem existências separadas e autônomas ${ }^{48}$.

Quando as decisões judiciais são baseadas na vontade dos juízes, elas sofrem de um letal déficit democrático ${ }^{49}$, o que acarretaria além da insegurança jurídica a subversão de todos ao sistema jurídico, a ponto de se chegar ao absurdo de se defender que a Constituição e as leis deveriam se adaptar aos Governos, não os Governos terem que conduzir suas práticas à Constituição e às leis ${ }^{50}$.

Desse modo, a hermenêutica eficaz não deve ser nem totalmente livre nem totalmente flexível, mas integrar-se ao constitucionalismo principiológico, a dimensão sistemática do ordenamento jurídico e observar dialeticamente as orientações doutrinárias ${ }^{51}$ e os precedentes judiciais

\footnotetext{
46 SILVEIRA, Denis Coitinho. O papel da razão pública na teoria da justiça de Rawls. Filosofia Unisinos, vol. 10, jan./abr. 2009, p. 77.

47 SCHNAID, David. Filosofia do direito e interpretação. Revista dos Tribunais.2004.p.213.

48 STRECK, Lênio Luiz. Hermenêutica juridical $e(m)$ crise: uma exploração hermenêutica da construção do direito. Porto Alegre:Livraria do Advogado, 2008. p.316.

49 STRECK, Lênio Luiz. O que é isto- decido conforme minha consciencia?Porto Alegre:Livraria do Advogado,2010. p. 85.

50 STRECK, Lênio Luiz. Constituição ou barbárie? - a lei como possibilidade emancipatória a partir do estado democrático de direito. p.9.

51 MARTIN, Andreia Garcia; PIGNATARI, Nínive Daniela Guimaraes. Op. cit. p.451.
} 


\section{CONCLUSÃO}

Se a aplicação do Direito estivesse sujeita à criação jurisdicional, colocar-se-ia em risco a segurança jurídica e o próprio Estado Democrático de Direito.

A discricionariedade judicial rompe a dinâmica do princípio da separação dos poderes (art. $2^{\circ} / \mathrm{CF}$ ), usurpando as funções do Poder Legislativo e acabando por desprezar a legitimidade democrática dos representantes eleitos diretamente pelo povo ${ }^{52}$.

Todavia, não se deve esquecer que o Direito é produto da linguagem, que deve e precisa ser interpretado. A fluidez do fenômeno jurídico exige uma hermenêutica flexível, mas que não conduza ao subjetivismo judicial, porque isso estaria a um passo do arbítrio, nefasto ao regime democrático.

Assim, a correta aplicação da norma jurídica está condicionada não à percepção de um intérprete em particular, mas ao contexto e à dialética social, compondo-se para a obtenção de soluções consensuais, envolvendo juízos morais, com uma pluralidade de colaboradores (razão pública $)^{53}$.

A vontade do julgador está limitada pelas fontes do Direito para não se produzir insegurança jurídica. Assim, a decisão judicial deve conduzir a interpretações convergentes com o sistema jurídico, com os precedentes judiciais e com a melhor orientação doutrinária. Com isso, afasta-se da discricionariedade judicial, que retirariam o caráter da estabilidade e da previsibilidade jurídicas.

Como consequência, esse modelo hermenêutico é capaz de produzir decisões autênticas, não vinculadas a concepções subjetivas do próprio julgador.

\footnotetext{
52 CAMBI, Eduardo. Processo constitucional e democracia. In: Direito constitucional brasileiro. Organização do Estado e dos Poderes. Vol. II. Coord. Clèmerson Merlin Clève. São Paulo: RT, 2014. p. 569-590.

53 "(...) identificada a dificuldade de uma fundamentação absoluta, que tomaria por pressuposto uma razão mais forte, a razão pública rawlseana possibilita uma orientação cognitivista para a determinação dos juízos morais, sendo mais forte do que nenhuma fundamentação e mais fraca do que uma fundamentação propriamente dita. $O$ critério objetivo de reciprocidade é construído tendo por base uma razão comum de todos os cidadãos que assumem um forte compromisso público com ideais e valores políticos, o que possibilita a construção dos princípios de justiça que estabelecem a defesa da igual liberdade, da igualdade equitativa de oportunidades e da diferença" (SILVEIRA, Denis Coitinho. 0 papel da razão pública na teoria da justiça de Rawls. Cit. p. 77).
} 


\section{REFERÊNCIAS}

ARRONE, Ricardo. Por uma nova hermenêutica dos direitos reais limitados. Rio de Janeiro: Renovar. 2001.

BAUMAN, Zygmunt .Modernidad Líquida.Buenos Aires:Fondo de Cultura Economica, 2002.

Janeiro: Zahar,1999

.Globalização: As consequiências humanas. Traducao Marcus Penchel .Rio de

BOBBIO Noberto. Teoria do Ordenamento Jurídico. Tradução de Ari Marcelo Solon. São Paulo: EDIPRO,2011.

BOBBIO, Noberto. A era dos Direitos. Tradução de Carlos Nelson Coutinho. São Paulo: Elsevier, 2004.

CAMBI, Eduardo; MARGRAF, Alencar Frederico. Casuísmos judiciários e precedentes judiciais. Revista de processo, vol. 248, out./2015.

CAMBI. Eduardo. Processo constitucional e democracia. In: Direito constitucional brasileiro. Organização do Estado e dos Poderes. Vol. II. Coord. Clèmerson Merlin Clève. São Paulo: RT, 2014.

. Neopositivismo e Neoconstitucionalismo. Direitos fundamentais, políticas públicas e protagonismo judiciário. São Paulo: Almedina. 2016.

SILVEIRA, Denis Coitinho. O papel da razão pública na teoria da justiça de Rawls. Filosofia Unisinos, vol. 10, jan./abr. 2009.

DWORIN, Ronald. Levando o direito a sério.São Paulo: Martins Fontes. 2011.

FALCÃO, João Emílio. Entrevista ao Jornal da Constituinte, no 63, caderno 1. 5 out. 1988.

GRAU, Eros Roberto. Porque tenho medo dos juízes (a interpretação/aplicação do direito e os princípios). São Paulo: Malheiros, 2013.

GUTEMBERG, Luiz. Mapa geral das idéias e propostas para a nova Constituição. Brasília: Ministério da Justiça/ Fundação Petrônio Portella, 1987

HABERMAS, Jürgen. Direito e democracia: entre facticidade e validade. $2^{\mathrm{a}}$ ed. Tradução de Flávio Beno Siebeneichler. Rio de Janeiro: Tempo Brasileiro, 2003.

.A inclusão do outro.Tradução George Sperber. São Paulo: Edições Loyola, 2002.

HARTH, Hebert L.A. O conceito de direito. Lisboa: Fundação Calouste Gulbenkian,2001. 
IKAWA, Daniela R. Hart, Dworkin e discricionariedade.Luanova, n 61- 2004.

LIMA, Tadeu Augimeri Goes de. Neoconstitucionalismo: um breve panorama.Argumenta Journal Law, Jacarezinho PR. 2015.

MACHADO. EdinilsonDonisete. Ativismo Judicial. Letras Jurídicas. São Paulo:2012.

MARTIN, Andreia Garcia; PIGNATARI, Nínive Daniela Guimaraes. A decisão Judicial sob a perspectiva do princípio da prevalência dos direitos humanos: A humanização da hermenêutica judicial. Birigui: Boreal, 2012.

MONCLAIRE, Stéphane. As grandes características do último processo constituinte brasileiro. Revista de informação legislativa, v. 45, n. 179, p. 277-295, jul./set. 2008.

RAWLS, John. O liberalismo político. Trad. Dinah de Abreu Azevedo. Brasília: Editora Ática, 2000.

RIBEIRO, Ronaldo Paixão. Maintenant, à lafindutunnel, brillelalumière. Entrevista ao Jornal da Constituinte. no 63, caderno 1. 5 out. 1988.

ROHMANN, Chris. O Livro das ideias: pensadores, teorias e conceitos que formam nossa visão de mundo. Rio de Janeiro: Campus,2000.

SCHLEIERMACHER, Friedrich D.E. Hermenêutica- Arte e técnica da interpretação.

Petrópolis,RJ:Vozes; SP:Editora Universitária São Francisco,2012.

SCHNAID, David. Filosofia do direito e interpretação. São Paulo: RT, 2004.

SILVA, Ovídio Araújo Baptista da. Processo e Ideologia: o paradigma racionalista. $2^{\mathrm{a}}$ ed. Rio de Janeiro: Forense, 2006.

STRECK, Lênio Luiz. Hermenêutica juridical e(m) crise: uma exploração hermenêutica da construção do direito. Porto Alegre: Livraria do Advogado, 2008.

O que é isto - decido conforme minha consciência?4. ed. Porto Alegre: Livraria do Advogado Editora, 2013.

. Constituição ou barbárie? - a lei como possibilidade emancipatória a partir do estado democrático de direito. Disponível em < https: / /ensaiosjuridicos.files.wordpress.com/2013/04/constituic3a7c3a3o-ou-barbc3a1riee28093-a-lei-como-possibilidade-lenio.pdf > acessado em 23.01.2016.

VIAL, Sophia martini. O fenômeno da codificação e da recodificação no Direito Privado. Irevista de direito privado, vol. 64, out./dez. 2015.

ZAGREBELSKY, Gustavo. Il diritto mite. Turim: Einadi, 1992. 
ISSN 1981-3694

(DOI): $10.5902 / 1981369421193$

REVISTA ELETRÔNICA DO CURSD DE

La ley e su justicia. Tres capítulos de justicia constitucional. Itália, 2007.

WAMBIER, Teresa Arruda Alvim. Precedentes e Evolução do Direito.In: Direito Jurisprudencial.

Coord. Teresa Arruda Alvim Wambier. São Paulo: Revista dos Tribunais, 2012.

Recebido em: 11.02.2016 / Revisões requeridas em: 24.03.2016 / Aprovado em: 02.04.2016 